\title{
El Programa de Autogestión para la Vivienda (PAV): algunos aspectos relevantes a la hora de pensar en las condiciones de vida de mujeres pertenecientes a sectores de bajos ingresos en la Ciudad Autónoma de Buenos Aires
}

\author{
Self-Management Program for Housing (PAV): some relevant aspects \\ when thinking about the lives of women from low-income sectors \\ in the Autonomous City of Buenos Aires
}

María Laura Gil y de Anso, Julia Ramos

\begin{abstract}
Resumen
La Ciudad de Buenos Aires (Argentina) comparte la tendencia latinoamericana del acelerado proceso de urbanización de la pobreza, registrando altos niveles de exclusión social y segregación socioespacial. Específicamente en materia habitacional, y pese a los compromisos asumidos, las políticas públicas que desarrolla el gobierno municipal en función de dar respuesta a los problemas relacionados con el acceso a la vivienda resultan insuficientes, convirtiendo a las mujeres de bajos ingresos en un grupo particularmente vulnerable a raíz del peso de sus múltiples roles culturalmente construidos (productivos, reproductivos y comunitarios). En este contexto, el presente artículo se focaliza, desde una perspectiva que intercepta los conceptos de género y hábitat, en el Programa de Autogestión para la Vivienda del Gobierno de la Ciudad de Buenos Aires, a raíz de sus potencialidades a la hora de pensar en la calidad de vida de las mujeres de sectores populares.
\end{abstract}

Palabras clave: políticas públicas de vivienda - sectores populares - género - derecho a la vivienda - derecho a la ciudad.

\begin{abstract}
Buenos Aires city (Argentina) shares the latinamerican trend toward of the accelerated process of poverty urbanization, registering high levels of social exclusion and social spatial segregation. Specifically, in housing matter, and in spite of the assumed commitments, the public policies that the municipal government develops according to response to the housing problems, are insufficient, turning the women of low incomes into a particularly vulnerable group as a result of the weight of their multiple roles, culturally constructed (productive, reproductive and communitarian). Within this framework, the present article focuses, from a perspective that intercepts the concepts of gender and habitat, in the 'Programa de Autogestión para la Vivienda', of the Government of Buenos Aires city, as a result of its potentialities relative to the life quality of women of popular sectors.
\end{abstract}

Key words: housing public policies - popular sectors - gender - right to housing - right to the city.

Doctoranda en Ciencias Sociales, Facultad de Ciencias Sociales, Universidad de Buenos Aires (UBA). Licenciada en Sociología. Becaria CONICET con sede en el Área de Estudios Urbanos del Instituto de Investigaciones Gino Germani (IIGG) de la Facultad de Ciencias Sociales, UBA. E-mail: juliamariaramos@gmail.com 


\section{INTRODUCCIÓN}

La Constitución de la Ciudad Autónoma de Buenos Aires (Argentina), sancionada en 1996, reconoce en su artículo № 31 el derecho a una vivienda digna y a un hábitat adecuado, estableciendo la resolución progresiva del déficit habitacional, de infraestructura y servicios, y dando prioridad a las personas de los sectores de pobreza crítica y con necesidades especiales de escasos recursos. Sin embargo, y más allá de este reconocimiento en el plano declarativo, Buenos Aires comparte la tendencia latinoamericana del acelerado proceso de urbanización de la pobreza, registrando altos niveles de exclusión social (Villarreal, 1996) y segregación socioespacial (Cravino, 2008). Pese a que en la actualidad resulta complejo obtener cifras oficiales acerca de la cantidad de personas que viven en una situación habitacional deficitaria, para el año 2006, y como una tendencia en ascenso, se calculaba que las condiciones de precariedad más aguda y de emergencia alcanzaban, como mínimo, al 15\% de la población porteña (Centro de Estudios Legales y Sociales [CELS], 2009).

Frente a este panorama acuciante, las políticas públicas que desarrolla el gobierno de la Ciudad de Buenos Aires en función de dar respuesta a los problemas relacionados con el acceso a la vivienda son -y han sido- insuficientes y de corte asistencial. De hecho, los programas que apuntan a reducir la situación de emergencia habitacional ${ }^{2}$ parten de un abordaje que no considera la heterogeneidad de la demanda social, reduciendo el problema a un déficit de tipo cuantitativo, sin identificar que la problemática del habitar la ciudad trasciende largamente el acceso a un techo. En este sentido, históricamente, y tanto en el ámbito de la Ciudad de Buenos Aires como a nivel nacional, se ha priorizado la construcción masiva de viviendas de interés social bajo el modelo "llave en mano"3, desconociendo factores como la localización o la calidad física de los inmuebles o la presencia suficiente de servicios e infraestructura. Así, este tipo de políticas que privilegia la construcción de vivienda nueva, teniendo como principales beneficiarias a las empresas constructoras, se muestra insuficiente para contener las necesidades de sus destinatarios, en general, y de sus destinatarias, en particular: nos referimos a las mujeres de sectores populares ${ }^{4}$ quienes, en función de sus múltiples roles culturalmente construidos (productivos, reproductivos y comunitarios), son especialmente vulnerables frente a las problemáticas relacionadas con el hábitat y la vivienda.

2 Se define la emergencia habitacional como aquella situación de vulnerabilidad habitacional que incluye población que habita viviendas deficitarias, en término amplio, y población en riesgo de ser expulsada de la vivienda (Gobierno de la Ciudad Autónoma de Buenos Aires, 2008).

3 Nos referimos a aquella producción de viviendas que, como característica destacada, implica la ausencia de participación de los/as destinatarios/as individuales y de cualquier organización en los procesos de construcción de su hábitat.

$4 \quad$ Siguiendo a Coraggio (1998), utilizaremos el calificativo "popular" para caracterizar a las familias que necesitan del trabajo, sea por cuenta propia o en relación de dependencia, como base necesaria de su reproducción. Según el autor, esta definición "no coincide, entonces, con las familias denominadas 'pobres', ni con las actividades denominadas 'informales', ni con la clase obrera o la campesina, aunque los incluye" (Coraggio, 1998: 12). 
Ahora bien, aun en este contexto hegemónico de respuestas homogeneizantes y de destinatarios y destinatarias pasivos/as, resulta interesante rescatar el caso del Programa de Autogestión para la Vivienda (PAV), dependiente del Instituto de Vivienda de la Ciudad Autónoma de Buenos Aires (IVC/GCABA). Si bien en su génesis el PAV no se propuso generar impactos específicos en la vida de las mujeres de menores ingresos, sino constituirse en una herramienta de acceso a la vivienda, presenta ciertos aspectos relevantes al momento de pensar en la calidad de vida de las mismas y con relación a la concepción de derecho a la ciudad.

En las siguientes páginas, entonces, se reflexionará sobre las características formales y de implementación de este programa, focalizando en sus repercusiones a nivel de la situación de las mujeres de sectores de bajos ingresos ${ }^{5}$ y en oposición a las tendencias hegemónicas en materia de políticas habitacionales dentro del territorio porteño. Para ello, se revisará bibliografía especializada acerca de la intersección de los conceptos de género y hábitat. Además, se considerarán normativas y una serie de documentos realizados por organismos de derechos humanos, organizaciones sociales y organizaciones de mujeres que trabajan alrededor de las temáticas del derecho a la vivienda y el derecho a la ciudad.

\section{UNA MIRADA DE GÉNERO HACIA EL ESPACIO URBANO: ALGUNAS PRECISIONES TEÓRICAS}

Este artículo se enmarca en una serie de esfuerzos que, tanto en el plano de la producción académica como a nivel de la agenda pública de los países latinoamericanos, se han desplegado durante los últimos años con relación al cruce entre género y hábitat. En este sentido, partimos de concebir a la categoría teórica de género como la construcción social de lo femenino y lo masculino que se expresa en la red de creencias, conductas, actitudes, valores y actividades que diferencian a los varones y a las mujeres. Según esta categoría de análisis se reconoce que las desigualdades sociales entre varones y mujeres no están determinadas por las diferencias de tipo biológicas, sino que son construidas histórica y socialmente (Salazar Cruz, 1999).

Los estudios que abordan la intersección entre la categoría de género y espacio urbano, en términos generales, parten de la necesidad de desnaturalizar y cuestionar las desigualdades relacionadas con el acceso a las oportunidades y a los bienes y servicios que ofrece la ciudad. Así, la incorporación de la dimensión de género en el estudio de las ciudades permite visibilizar y reconocer que el espacio no es neutro ni desgenerizado y que los roles sociales y mandatos culturales que desempeñan varones y mujeres condicionan la forma en que acceden y usan la ciudad, así como sus modos de percibirla y apropiarse de ella en sus vidas cotidianas (Saborido, 1999). Partiendo de esta mirada teórica, desde distintos ámbitos se vienen desarrollando estudios que abordan una gran diversidad de temas: los usos del espacio y del tiempo y los

5 Es fundamental aclarar que si bien abordaremos la relación entre mujeres, hábitat y políticas públicas, no se pierde de vista que esta vinculación está atravesada por relaciones sociales de género. 
recorridos urbanos de mujeres y varones; las desigualdades de género en cuanto al acceso a la vivienda y al hábitat adecuado; la activa participación de las mujeres en la lucha por la vivienda y por la producción social del espacio urbano; el problema de la violencia de género expresada en las ciudades, y el acceso femenino a equipamientos sociales e infraestructura urbana, entre otras temáticas (Herzer, Di Virgilio y Rodríguez, 2006). Asimismo, desde distintos organismos internacionales y nacionales se ha consensuado sobre la necesidad de incorporar la visión de las mujeres, en tanto ciudadanas con intereses específicos, a la planificación de las ciudades y al desarrollo de distintas políticas públicas.

Este foco puesto en la relación que las mujeres mantienen con el espacio urbano permite visibilizar cómo los múltiples roles socialmente construidos que recaen sobre ellas adquieren expresión territorial por sus recorridos en las ciudades. En este sentido, los usos, desplazamientos y apropiaciones del espacio urbano que describen, particularmente las mujeres de sectores populares, suelen vincularse con su triple rol por estar a cargo de la reproducción y el cuidado familiar, del desempeño de un trabajo remunerado en el mercado laboral y de las tareas de tipo comunitarias o de servicios voluntarios o de participación en organizaciones sociales. Así, estas mujeres se convierten en las principales usuarias del barrio, de las viviendas, de los servicios y equipamientos colectivos, siendo este uso reflejo de la división sexual del trabajo y encontrándose obstaculizado, en muchas ocasiones, por la organización física y social de las ciudades y su planificación basados en ciertos criterios de zonificación de actividades ${ }^{6}$, que no hacen más que traducir la ideología patriarcal en la configuración del espacio urbano (Massolo, 1999). Esta inadecuación entre la localización residencial de las mujeres y las diversas actividades que desarrollan supone, entonces, largos desplazamientos en insuficientes medios de transportes -y con altos costos económicos-, que traen como correlato un mayor insumo de tiempo y esfuerzo físico en su jornada (laboral y/o laboral no remunerada).

La Ciudad de Buenos Aires no ha permanecido ajena a estos procesos. De hecho, junto con un recrudecimiento de las condiciones de vida de los sectores populares en los últimos años, las mujeres se han visto particularmente perjudicadas, ya que tanto en la estructura del espacio como en el diseño de las políticas públicas habitacionales y urbanas se puede identificar ciertas visiones estereotipadas acerca de los roles femeninos y masculinos, que implican altos costos para ellas al tener que conjugar necesariamente su trabajo dentro y fuera de la esfera privada.

\section{EL CONTEXTO PORTEÑO Y LA SITUACIÓN DE LAS MUJERES}

La Ciudad de Buenos Aires, desde mediados de los 90, viene atravesando un proceso de agudización de la desigualdad social respecto del acceso a los bienes y servicios que ofrece el espacio urbano para la producción y reproducción de la vida.

- A su vez, estos métodos de zonificación que dividen a las ciudades en áreas residenciales, comerciales, financieras, administrativas, naturalizan y refuerzan la división sexual del trabajo por la que el espacio productivo-público es asignado tradicionalmente a los varones y el espacio doméstico-privado es asignado a las mujeres (Falú, 2003). 
Esto último se observa claramente en el plano de la salud, la educación, la vivienda y el acceso a las fuentes de trabajo, pudiéndose identificar impactos diferenciales no solo por estratos socioeconómicos, sino también según se trate de varones o mujeres dentro de un mismo grupo social.

Esta realidad se conjuga con otros fenómenos que se despliegan en la ciudad, como la segregación socioespacial, la precariedad habitacional, el hacinamiento o la falta de seguridad en la tenencia de los inmuebles, afectando de manera rotunda la vida cotidiana de las mujeres más pobres, en muchos casos, únicas sostén del hogar? A su vez, se pueden mencionar otras problemáticas urbanas que las afectan y condicionan, como el deterioro de la calidad medioambiental, la provisión insuficiente de equipamiento (transporte, espacios verdes, instituciones educativas, etc.) y servicios urbanos (agua, recolección de basura, etc.), y el fenómeno de la violencia expresada en el espacio urbano (Herzer, Di Virgilio y Rodríguez, Op. cit.).

En los últimos años, Buenos Aires en su conjunto ha experimentado un proceso de encarecimiento del mercado formal inmobiliario que complejiza aún más la problemática del acceso a la vivienda para los sectores de menores ingresos, quienes, para resolver su condición habitacional, deben recurrir a alguna forma de hábitat popular: ocupaciones de inmuebles o tierra vacante (pública y/o privada), alquiler de habitaciones en hoteles-pensión, alquiler de piezas en villas ${ }^{8}$ (en casas de familia o en inquilinatos), compra de lotes y/o casas en villas o formas organizadas de producción social del hábitat?

Respecto de aquellos fenómenos urbanos que afectan particularmente la vida cotidiana de las mujeres más pobres, podemos destacar los procesos de renovación urbana que se desarrollan en barrios en los que históricamente habitaban familias de bajos ingresos como San Telmo, Barracas y La Boca. La valorización inmobiliaria dentro de estos barrios de la zona sur de la Ciudad, impulsada por operaciones de renovación y revitalización urbana por parte de actores públicos y privados, ha generado un proceso de recambio poblacional, reemplazando a un grupo de residentes por otro

$7 \quad$ Esto, en medio de un contexto latinoamericano de creciente feminización de la pobreza. Si bien a nivel regional, y desde el año 2003, se ha observado una disminución total de los hogares pobres e indigentes, este hecho no se condice con la situación de muchas mujeres, cuya representación entre estos hogares ha aumentado más que la de los varones: por cada 100 varones en los hogares indigentes había 118 mujeres en 1990, 125 en 2005 y 130 en 2008 (Naciones Unidas, 2010).

8 Las villas, como tipología de hábitat popular, son "enclaves urbanos de pobreza" (Oszlak, 1991), que se caracterizan principalmente por su trama irregular en el espacio. Se ubican en parcelas fiscales y también en terrenos privados no utilizados. La constitución espacial no responde al tablero característico de Buenos Aires, sino que son pequeños pasillos y calles que se cruzan sin una previa lógica organizativa. Sus principales características son: insalubridad, precariedad habitacional, hacinamiento, ausencia de servicios, etcétera.

$9 \quad$ Los procesos de producción social del hábitat (PSH) constituyen una forma específica dentro del conjunto de modalidades de autoproducción del espacio urbano ejecutadas históricamente por los sectores populares latinoamericanos. Este concepto agrupa varias formas de producción de vivienda y hábitat que comparten el hecho de haber sido concebidas de manera planificada y que son dirigidas por colectivos u organizaciones sociales (Rodríguez et al., 2007). 
de mayor estatus social (Herzer, 2008) ${ }^{10}$. En este sentido, muchísimas familias han debido mudarse a zonas acordes con sus ingresos al ser expulsadas de los barrios en donde su vida se desarrollaba y teniendo que instalarse en lugares alejados del centro de la ciudad, con la consiguiente pérdida de las redes sociales construidas a lo largo de los años. Este fenómeno ha afectado de forma particular la vida de las mujeres, para quienes el hecho de vivir en lugares centrales, cercanos a los lugares de trabajo y dotados de servicios sanitarios, educativos y culturales, infraestructura y medios de transportes es sumamente importante para poder desarrollar sus múltiples actividades productivas y reproductivas.

También podemos mencionar la situación que atraviesan los hogares residentes en los conjuntos habitacionales del sur de la Ciudad (de los barrios de Villa Lugano o Villa Soldati, por ejemplo), donde se observa un alto grado de deterioro físico tanto en los departamentos como en los edificios e instalaciones. Se trata de complejos FONAVI ${ }^{11}$ que responden a modelos habitacionales estandarizados que no permiten la realización de obras de ampliación para alojar a nuevos hogares. En muchos casos, entonces, se observan serias situaciones de hacinamiento, ya que las nuevas generaciones, al no poder acceder a otra vivienda, deben permanecer en sus hogares maternos/paternos. Este hecho repercute negativamente en la vida de las mujeres tanto por agravar sus condiciones de vida como por la frustración que les genera la imposibilidad de adosar a sus viviendas un espacio para sus hijos emparejados y sus familias (Saborido, Op. cit.).

En este contexto, la cuestión del acceso a la vivienda para las mujeres de menores ingresos se torna una problemática particularmente difícil y su análisis resulta un eje fundamental cuando se piensa en sus condiciones de vida, debido a que no solo constituye el ámbito desde donde organizan la vida familiar, sino que representa un espacio físico en el que permanecen mucho tiempo (Ducci, 1994). En este último sentido, y ante las difíciles condiciones económicas, en muchos hogares pobres (y no tan pobres) se desarrollan emprendimientos o iniciativas productivas en el ámbito doméstico, convergiendo así en un solo espacio los roles femeninos reproductivo y productivo, y generando deterioros importantes en los espacios de la vivienda que ya son mínimos y precarios.

Entre los principales factores que inciden negativamente en este acceso a la vivienda destacamos la forma que asume la inserción femenina en el mercado laboral ${ }^{12}$. Este punto constituye uno de los pilares de las desigualdades sociales que las afectan, posicionándolas en una situación de mayor vulnerabilidad, y se caracteriza por una inserción precaria y remuneraciones proporcionalmente más bajas que los varones

10 En el marco de este proceso, muchos hoteles-pensión, donde residían cientos de familias de bajos ingresos, fueron cerrando, vendiendo el inmueble para nuevas construcciones o simplemente continuaron siendo hoteles, pero destinados al turismo. Las familias que residían en estos hoteles-pensión -en pésimas condiciones, por ciertodebieron buscar nuevos lugares en otras zonas de la ciudad o de la periferia, cediendo así centralidad urbana. Las características de los tipos habitacionales FONAVI serán abordadas más adelante.

12 Un alto porcentaje de mujeres de bajos ingresos no cumple con los criterios de elegibilidad para el acceso a la vivienda subsidiada que promueven las políticas habitacionales de la Ciudad (y a nivel nacional también), ya que estas presuponen ingresos regulares y empleos formales, mientras que los ingresos de las mujeres pobres, en muchos casos, provienen de empleos informales e inestables. 
por el mismo trabajo. Estos fenómenos que afectan particularmente a la fuerza de trabajo femenina se han conjugado, en las últimas décadas, con otras características que ha adquirido el mercado laboral (mayor flexibilización, pérdida de calidad de los empleos del sector formal, deterioro salarial, mayor inseguridad y prolongación de la jornada de trabajo), derivando en un menor acceso al crédito o al mercado de alquiler formal para adquirir una vivienda digna (por no poder demostrar ingresos y/o por no contar con ingresos suficientes).

\section{LAS POLÍTICAS DE ACCESO A LA VIVIENDA:TENDENCIAS HEGEMÓNICAS Y EL CASO DEL PROGRAMA DE AUTOGESTIÓN PARA LA VIVIENDA (PAV)}

Siguiendo a Gomá y Subirats (1999), concebimos a las políticas públicas como expresiones de entramados en los que convergen múltiples actores sociales, políticos y económicos, y en donde el gobierno tiene un papel estratégico al poner en juego los recursos del Estado en los procesos de reproducción y/o recreación de las relaciones sociales y de poder. Específicamente en materia de hábitat y vivienda, Oszlak (1991) sostiene que las políticas presentan un conjunto de acciones y omisiones que manifiestan la intervención del Estado con relación a la distribución/localización de los diferentes sectores sociales en la ciudad y, consecuentemente, con la satisfacción diferencial de ciertas necesidades básicas. Según este punto de vista, las políticas habitacionales no se reducen a la expresión normativa de una presunta voluntad del Estado, sino que, además, se manifiestan en un conjunto de tomas de posiciones que reflejan una cierta filosofía política en el contexto de relaciones desiguales de poder y dominación.

Según Rodríguez et al. (2007), el análisis de la intervención del Estado por medio de sus políticas habitacionales y las modalidades de producción que las mismas sustentan o fomentan, permite dar cuenta de: a) cómo se distribuyen los bienes y el acceso a ellos en la sociedad y en qué medida las políticas contribuyen a una distribución y acceso más equitativos; b) cómo se equilibran o no las relaciones de fuerza y la posesión de recursos entre los distintos sectores, grupos y clases sociales; c) cómo se garantiza o no el derecho a la ciudad, entendido este como el derecho al goce de las oportunidades sociales y económicas asociadas a la localización de la vivienda; d) cómo se facilitan o no procesos de autonomía entre los sectores populares, al entender la vivienda como derecho humano fundamental; e) cómo se da respuesta o no a necesidades habitacionales esenciales mediante procedimientos variados; y f) cómo se incorpora o no en las políticas la noción de proceso en la producción y gestión del hábitat popular. De este modo, las políticas habitacionales, ya sea por acción u omisión, siempre implican consecuencias para las relaciones de clase y, también, de género.

Así entendido el rol del Estado en sus distintos niveles, en el caso de la Ciudad de Buenos Aires, este aparece, por un lado, como reproductor de la lógica neoliberal de apropiación del espacio urbano, al propiciar el desarrollo de grandes emprendimientos inmobiliarios privados. Pero, al mismo tiempo, genera respuestas, con distintos niveles de interacción con sus destinatarios, para resolver las múltiples problemáticas que el mismo modelo de ciudad capitalista genera. 
En este marco, las políticas habitacionales destinadas a los sectores de menores ingresos e históricamente ejecutadas tanto por el Gobierno de la Ciudad como por el gobierno nacional en el marco de la Ciudad, han estado orientadas a la producción masiva de viviendas nuevas, sin tener en cuenta la calidad física de las mismas ni factores como la localización, el mantenimiento de los espacios comunes y servicios, el abastecimiento suficiente de infraestructura comunitaria (escuelas, hospitales, transportes) o las necesidades particulares de las poblaciones destinatarias ${ }^{13}$. Incluso, y debido a la gravedad del déficit habitacional porteño, la gestión pública implementó una serie de programas sociales con el fin de cubrir dicha emergencia ${ }^{14}$. Ahora bien, estas iniciativas se caracterizan por ser fundamentalmente de corte asistencial, bastante erráticas y desarticuladas entre sí y según los diversos organismos estatales que las implementan. Así, no es extraño que esta multiplicidad de programas habitacionales haya tenido, en general, un alcance acotado en la población de bajos ingresos, porque la mayoría de las líneas de acción apunta a mejorar de forma superficial y transitoria su situación habitacional, sin llegar a establecer vinculaciones con políticas de acceso al suelo urbano que garanticen el derecho a la ciudad de los sectores populares.

Asimismo, los lentos planes de urbanización de las villas de la Ciudad por parte del gobierno local dan continuidad a situaciones de precariedad habitacional, hacinamiento y segregación sociorresidencial. La vida de las mujeres en este tipo de hábitat popular presenta serias dificultades relacionadas tanto con la localización periférica como con la precariedad de las viviendas y del acceso a servicios básicos como agua, luz y sistemas de desagües cloacales, que implican un esfuerzo extra por parte de las mismas a la hora de satisfacer las necesidades materiales de sus familias. Por otra parte, se observa también una importante política de entrega de subsidios ${ }^{15}$ tanto a habitantes de hoteles-pensión (para que residan de forma "transitoria" en una pieza alquilada) como a familias que fueron desalojadas de inmuebles privados o públicos, con el fin de que busquen otro lugar donde vivir.

Como vemos, este tipo de políticas no ha podido contemplar en su diseño, ejecución y alcance las singularidades de la vida cotidiana de las mujeres ${ }^{16}$ en función de sus múltiples roles culturalmente construidos, reproduciendo y reforzando, en muchos casos, las relaciones de subordinación entre varones y mujeres al no desafiar el modelo

13 Un ejemplo paradigmático de este tipo de operatorias públicas de producción de viviendas "Ilave en mano" para sectores de bajos ingresos, ejecutadas por el Estado nacional, está dado por las acciones del Fondo Nacional de la Vivienda que, hasta fines de los 90, concentraron de manera prominente las asignaciones presupuestarias nacionales en el sector vivienda. Desde su creación en 1972 como un dispositivo político, institucional y financiero de gran envergadura, el FONAVI fue concebido como un fondo continuo para el financiamiento de la vivienda.

14 Nos referimos a las medidas tomadas después de la sanción de la Ley Nº 1408 que declaró en emergencia habitacional a la Ciudad de Buenos Aires en el año 2004.

15 Pensamos en el Programa "Vivienda Transitoria/Programa apoyo habitacional", del Gobierno de la Ciudad de Buenos Aires, que se propone:"posibilitar a las personas (...) alojadas en hoteles que puedan optar por única vez, entre percibir un monto en concepto de subsidio o crédito hipotecario, con el objeto de contribuir al logro de soluciones habitacionales de mayor estabilidad o a la adquisición de inmuebles destinados a vivienda" (GCABA, 2011:s/p).

16 A su vez, cabe decir que por lo general tampoco arbitran acciones positivas en su favor como incentivos o subsidios especiales para el acceso a la vivienda. 
de ciudad excluyente que expulsa a los sectores de bajos ingresos hacia las periferias. En efecto, específicamente en materia de localización de las viviendas, puede decirse que en las acciones implementadas se trasluce cierta tendencia expulsora. Teniendo en cuenta la importancia creciente que ha adquirido la centralidad, la segregación física de los asentamientos o de los nuevos barrios construidos en carácter de relocalizaciones en sectores periféricos refuerza la exclusión de las mujeres de sectores populares al alejarlas de las fuentes de empleo, significando, en muchos casos, una pérdida de puestos de trabajo por las distancias y los elevados costos de traslado. La Carta Internacional por el Derecho de las Mujeres a la Ciudad (Foro Mundial de las Mujeres, 2004) destaca esta tensión entre el acceso a la vivienda y su localización, destacándola como uno de los principales obstáculos de las mujeres para su autonomía en condiciones favorables. En este sentido, y pese a las declaraciones y compromisos asumidos por el Estado argentino en sus distintos niveles, se observa que las políticas urbanas y habitacionales continúan en gran medida asumiendo un concepto limitado de vivienda, sin considerar la interdependencia de la misma con el acceso al empleo, los servicios públicos, las redes de infraestructura y la calidad ambiental, con consecuencias para la vida de la población y, especialmente, de las mujeres.

Frente a este tipo de respuestas uniformes y estandarizadas, se puede sostener concretamente que hay dimensiones de los derechos a la vivienda y a la ciudad de las mujeres que quedan sin resolver aun después de convertirse en "beneficiarias" de alguna política habitacional (Gil y de Anso y Ramos, 2010a).

Por último, resulta necesario mencionar que en los últimos años ha disminuido de forma alarmante el presupuesto ${ }^{17}$ para un programa que persigue soluciones integrales de mayor alcance, que ha contenido la demanda de las organizaciones sociales y que promueve instancias participativas y autogestionarias: el Programa de Autogestión para la Vivienda.

\section{EI PAV ${ }^{18}$}

Este programa, ejecutado por el Instituto de Vivienda de la Ciudad Autónoma de Buenos Aires, constituye la operacionalización o implementación de la Ley Nº 341 (año 2000) y su posterior modificación, la Ley No 964 (año 2002). Esta operatoria está destinada a instrumentar políticas de acceso a la vivienda para uso exclusivo y permanente de hogares de escasos recursos en situación crítica habitacional, asumidos como destinatarios individuales o incorporados en procesos de organización colectiva, por cooperativas, mutuales o asociaciones civiles sin fines de lucro, mediante subsidios o créditos con garantías hipotecarias. El PAV se propone financiar tanto obras nuevas como la rehabilitación y el mejoramiento de viviendas, y su sanción representó, en

17 Esta disminución se ha traducido en el congelamiento del acceso a nuevos créditos y en numerosos obstáculos para el desarrollo de los proyectos ya en ejecución.

18 Entre otras fuentes, la información relativa al Programa de Autogestión para la Vivienda se encuentra disponible en la página web del gobierno de la Ciudad de Buenos Aires (http://www.buenosaires.gov.ar). 
un primer momento, un reconocimiento por parte del Estado de la legitimidad de la autogestión como práctica. En su enunciación formal, el programa se propone, por un lado, resolver la problemática habitacional de un sector social que no califica en el mercado inmobiliario formal y, por otro, fortalecer y fomentar procesos cooperativos, transfiriendo recursos y capacidades a las entidades que son incorporadas al proceso como sujetos activos en la ejecución de la política pública.

Los destinatarios del PAV acceden a un crédito blando para la compra, remodelación y/o construcción de unidades habitacionales. La transferencia de los fondos se encuentra a cargo del Instituto de Vivienda de la Ciudad y se realiza en etapas conforme al desarrollo de la obra. En el caso de las cooperativas, los integrantes asumen la responsabilidad de administrar los recursos y reintegrar los créditos, convocando a un equipo profesional interdisciplinario para brindar un acompañamiento técnico ${ }^{19}$.

Una de las características principales del PAV fue la participación directa de distintas organizaciones sociales que luchan por la vivienda ${ }^{20}$ en la fase de definición y diseño de la política, lo que dio lugar a un programa adaptable a las necesidades y características de los destinatarios. Por lo tanto, la gestación de este tipo de operatoria, a diferencia de otras desarrolladas por el gobierno de la Ciudad y más allá de las contingencias políticas, implicó un cambio importante en la relación entre las organizaciones sociales y los organismos estatales, impulsando una transformación y democratización de las políticas publicas ${ }^{21}$. Según Rodríguez (2002), esto es fruto de un proceso de interacción donde las relaciones entre la sociedad civil y el Estado son resignificadas una vez que la identificación de necesidades específicas y la consiguiente generación de respuestas políticas involucran a la población destinataria como sujeto activamente participativo.

Resulta interesante recalcar, a su vez, el hecho de que el PAV garantiza la permanencia de los sectores de menores ingresos, destinatarios de esta política, en el territorio de la Ciudad de Buenos Aires, cuestión que rompe con la tendencia de "ubicarlos" en las zonas más relegadas del espacio urbano. Las organizaciones sociales que acceden al crédito hipotecario son las encargadas se buscar en el mercado inmobiliario el terreno o el predio en donde se construirán las futuras viviendas. Y si bien esta "búsqueda" presenta ciertas complicaciones, ya que los tiempos burocráticos no se adecuan al ritmo del mercado inmobiliario, implica un avance -o una ruptura- en la posibilidad de elegir dónde vivir por parte de los destinatarios del PAV. El hecho de poder permanecer en barrios céntricos como San Telmo, Barracas, Constitución, Almagro o San

19 Este equipo debe estar formado por: i) ingenieros o arquitectos, a cargo de orientar la selección del terreno, desarrollar el proyecto arquitectónico y dirigir la construcción de la obra; ii) profesionales del área social como trabajadores sociales, sociólogos o psicólogos sociales, que intervengan en el fortalecimiento organizativo; iii) abogados que brinden asesoramiento jurídico durante el curso del proyecto, y iv) personal administrativo, que brinde asistencia en el plano administrativo/contable.

20 Como el Movimiento de Ocupantes e Inquilinos (MOI).

21 Con relación a esta participación, cabe destacar que si bien los actores involucrados tuvieron un rol activo durante la fase de diseño de la política y no en la fase de puesta en marcha, quedaba abierto e institucionalizado el espacio de la Comisión de Control, de Evaluación y Seguimiento que ha tenido durante estos años escasos niveles de constitución, reconocimiento por parte del Estado y poder de presión. 
Cristóbal repercute positivamente en la vida cotidiana de las mujeres, ya que además de alcanzar una vivienda definitiva y de alta calidad -para ellas y sus familias-, acceden a infraestructura urbana, a la cercanía a los puestos de trabajo, a servicios públicos y transportes, a espacios verdes, a centros educativos, culturales y de esparcimiento.

\section{POTENCIALIDADES Y TENSIONES DEL PAV RESPECTO DE LOS POSIBLES IMPACTOS EN LA VIDA DE LAS MUJERES}

EI PAV resulta un programa innovador, ya que entre sus objetivos se encuentra el fomento a experiencias de autogestión social del hábitat a cargo de organizaciones sociales, como cooperativas de vivienda. En este sentido, el impulso de este tipo de procesos por parte del Estado local implica un giro o una redefinición de la cultura política (Ibíd.) hacia una mayor participación de los sectores de menores ingresos, oponiéndose al tradicional abordaje asistencial de las políticas orientadas a la superación de la pobreza urbana. Esta participación se observa principalmente en que son las mismas organizaciones las que gestionan los recursos públicos (económicos y técnicos), dando cuenta, por un lado, del reconocimiento por parte del Estado de las capacidades de las mismas para conducir procesos de producción habitacional y, por otro, de un viraje profundo en el rol de las personas destinatarias: pasando de ser beneficiarias pasivas de unidades habitacionales estandarizadas a ser productoras organizadas y activas de la vivienda y el hábitat ${ }^{22}$.

Los destinatarios y destinatarias tienen la libertad de elegir a las personas con quienes desean asociarse con el objeto de solicitar el crédito. Este hecho, que repercute a futuro por tratarse de aquellos con quienes se vivirá en vecindad, resulta muy importante para las mujeres de sectores de bajos ingresos, ya que para poder cubrir sus múltiples tareas y encargarse del cuidado y crianza de los niños, construyen lazos y redes de apoyo con vecinas, amigas y familiares.

Asimismo, los beneficiarios del PAV pueden optar por una determinada forma asociativa (cooperativas, asociaciones civiles o mutuales, entre otras). Una vez organizados, tienen posibilidad de elegir la ubicación del terreno o del inmueble ${ }^{23}$, la modalidad a la que recurrirán para edificarlo (a partir de la contratación de empresas constructoras, cooperativas de trabajo o ayuda mutua, entre otras formas) y a los profesionales que conformarán el equipo técnico que acompañará el proceso de producción de las viviendas (Thomasz, 2008).

Las posibilidades que abre el PAV a un diseño participativo generan un fuerte impacto en la vida de las mujeres, ya que mediante la organización de talleres u otras

22 Si se observan las experiencias cooperativas del Movimiento de Ocupantes e Inquilinos, del Movimiento Territorial de Liberación o de la organización social Los Pibes en la Ciudad de Buenos Aires, vemos que, además de casas, se construyen equipamientos comunitarios como espacios de juegos, salones de uso múltiple y otras iniciativas, como jardines maternales y bachilleratos populares, que están abiertos a los vecinos del barrio. Por ello puede decirse que, además de viviendas, están construyendo ciudad. 
instancias de consulta pueden dar a conocer sus preferencias y gustos con relación a la distribución y dimensiones de los ambientes dentro de los inmuebles, la estética del complejo habitacional y la posibilidad de contar con espacios de uso común (como salones de usos múltiples, piscinas, bibliotecas, talleres de artesanías). Esta interpelación les devuelve a las mujeres un papel protagónico en la gestión de su hábitat, reivindicando sus saberes y conocimientos como principales usuarias de las viviendas.

Se trata, entonces, de una iniciativa que pone en tensión al resto de las políticas públicas orientadas a cubrir la demanda habitacional que, por lo general, no contienen las necesidades particulares de las mujeres de los sectores populares en función de sus múltiples roles culturalmente construidos. En este sentido, se podría decir que las operatorias que propician la autogestión, demandando una participación comunitaria constante, permiten superar los abordajes homogeneizantes: nadie mejor que los mismos usuarios y usuarias para dar cuenta de sus necesidades particulares respecto del hábitat (Gil y de Anso y Ramos, 2010b).

Como puede observarse, el PAV está en sintonía con la batería de consideraciones y reivindicaciones que, en referencia a la articulación entre políticas habitacionales y dimensión de género, realizan desde hace mucho tiempo diversos espacios ligados al feminismo o a organizaciones que luchan por mejorar las condiciones de vida de las mujeres. Entre estas recomendaciones, destacamos como eje fundamental la participación activa de las mujeres (y los varones, por supuesto) tanto en el diseño de las políticas sociales y de hábitat como en el proceso mismo de ejecución de los instrumentos, al formar parte de distintas instancias de toma de decisión (Michaud, 2007). Y es así que se sostiene la idea de que el PAV, directa o indirectamente, genera impactos positivos en la vida cotidiana de las mujeres de sectores populares, ya que a partir de su compromiso con la autogestión pueden ser contenidas sus necesidades específicas e influir en el diseño y la ubicación de la vivienda. En este sentido, y en clara oposición a la tradicional forma estandarizada que asumen las unidades habitacionales producidas históricamente por parte del Estado, este programa posibilita un diseño participativo en el que mujeres y varones pueden plasmar sus requerimientos y gustos con relación al hábitat.

Por su parte, promover la autogestión no solo implica el acceso a un techo y a un entorno urbano, sino que también habilita un proceso -lento, pero sostenido- de construcción de nuevas relaciones sociales de género -o al menos marcados procesos de empoderamiento de las mujeres- que se observan, sobre todo, en los roles que desempeñan tanto varones como mujeres y en las formas en que se distribuyen las responsabilidades domésticas al interior de las familias. Estas transformaciones van de la mano de los nuevos espacios que las mujeres pasan a ocupar cuando las políticas públicas habilitan una participación activa.

Por ejemplo, las mujeres profundizan sus capacidades para gestionar y administrar recursos en función de intereses u objetivos comunes. Como sostienen Rodríguez et al. (Op. cit.), los procesos autogestionarios suponen la participación para la toma de 
decisiones acerca de la utilización de los fondos públicos destinados a la construcción de las viviendas e implican tener que organizarse para planificar y ejecutar las distintas etapas de la obra de la manera más eficaz. En este marco, los espacios de participación de las mujeres dentro de organizaciones sociales como el Movimiento de Ocupantes e Inquilinos (MOI) son múltiples y se observa que progresivamente pasan a ocupar cargos directivos y de gran responsabilidad política (presidentas de cooperativas, coordinadoras de proyectos y equipos de trabajo, referentes de la organización en otros espacios), aun siendo mujeres que, en la mayoría de los casos, nunca habían tenido experiencia de participación política o comunitaria.

Además de incidir positivamente en su autoestima, el hecho de participar en las distintas instancias que suponen los procesos de autogestión genera entre las mujeres nuevos desplazamientos y formas de apropiación del espacio barrial y de la ciudad, ayudando a muchas a romper con una historia de confinamiento en el ámbito privado. A esta circunstancia contribuye también la posibilidad que habilita el PAV de construir los inmuebles mediante ayuda mutua, lo que implica un aporte concreto de mano de obra de los destinatarios y destinatarias para abaratar los costos de la obra. Si nos detenemos en la experiencia del $\mathrm{MOl}$, se puede observar cómo las mujeres de distintas edades trabajan en la obra junto a los varones -con o sin experiencia en construcción-, desafiando la ideología patriarcal que naturaliza ciertos roles o "lugares de la mujer"y originándose un espacio de aprendizaje y de solidaridad donde, sobre todo los varones, comienzan poco a poco a ver más allá de los estereotipos femeninos.

De esta manera, la vivienda funcionaría como un resorte que impulsa la salida de las mujeres de sectores populares a la escena pública, con todos los obstáculos, censuras y violencias que ello conlleva, mientras las organizaciones sociales que promueven los procesos de autogestión (de la mano de alguna política pública) se convierten en potenciales terrenos fértiles para que se desarrollen como sujetos sociales y ciudadanas (Massolo, Op. cit.). En este sentido, y por el análisis de la experiencia del MOI (Gil y de Anso y Ramos, 2011), pueden observarse indicios de cierto viraje desde una actitud pasiva y vinculada al rol de madre, esposa y ama de casa, hacia un nuevo perfil activo que demanda, lucha por sus derechos, gestiona recursos, protesta, negocia y ejerce influencia sobre otros.

Asimismo, y si consideramos que históricamente las mujeres han atravesado obstáculos particulares con relación a la seguridad de la tenencia y con la titularidad de las unidades habitacionales -hechos que atentan contra las posibilidades de una vida estable, autónoma, sin la amenaza constante del desalojo ${ }^{24}$-, la posibilidad que habilita el PAV respecto del acceso a créditos hipotecarios mediante un colectivo y sin presentar requisitos limitantes para formar parte de las organizaciones sociales (como por ejemplo, la demostración de ingresos), reviste una gran importancia para

$24 \quad$ A su vez, en el caso de situaciones de violencia de género al interior del espacio doméstico, el hecho de no contar con la seguridad de la tenencia limita las posibilidades de abandonar a un compañero abusivo, perjudicando la vida emocional y física de las mujeres y sus hijos. 
la calidad de vida de las mujeres, principalmente aquellas que están solas a cargo de sus familias. Es preciso aclarar que, si bien en la actualidad este problema no tiene que ver estrictamente con impedimentos legales sino más bien ligados a limitaciones de las propias políticas públicas de acceso a la vivienda, a prácticas culturales y a las condiciones en las que las mujeres se insertan en el mercado laboral (entre otros factores), lo cierto es que las mujeres se ven afectadas de forma desproporcionada -con relación a los varones- por los desalojos forzosos y las relocalizaciones. Por lo tanto, el goce de seguridad de la tenencia es esencial para combatir la desigualdad en las relaciones entre mujeres y varones, afirmando el derecho de las mismas a vivir una vida de forma independiente.

En este mismo sentido, y si se observan experiencias concretas como la del MOl, vemos que al interior de las organizaciones sociales se construyen lazos de solidaridad: si se da el caso de que una familia, por motivos laborales o personales, no logre estar al día con la cuota que debe pagar a la cooperativa (razón social que ha adquirido el crédito hipotecario ante el IVC), es la organización la que responde por ella. También resulta frecuente, entre las cooperativas de vivienda que construyen por medio de la Ley $N^{\circ} 341$, que desarrollen mecanismos de ahorro colectivo para cubrir el déficit que se pudiera generar ante la falta de pago de las cuotas mensuales por parte de alguna familia miembro y asegurando la permanencia de esta en la vivienda.

Si bien todas estas consideraciones muestran impactos positivos en la vida cotidiana de las mujeres, no podemos dejar de plantear un punto que genera ciertas tensiones y que abre nuevos cuestionamientos para futuras indagaciones. Tal como sostiene Jelin (1993), el "futuro liberador" - de las situaciones de opresión vividas por las mujeres al interior del espacio doméstico- que promete el hecho de ser parte de estos procesos que, sin duda, potencian transformaciones en la vida material y subjetiva de sus miembros, muchas veces se convierte en una nueva forma de reforzar la subordinación femenina por la sobrecarga de responsabilidades que implica para las mujeres tener que cumplir con las obligaciones derivadas de la autogestión, con las tareas reproductivas y, en muchos casos, con el desempeño de un trabajo remunerado. El dilema, entonces, radica en satisfacer las necesidades concretas de vivienda y hábitat de las mujeres de bajos ingresos sin caer en situaciones que alimenten viejas o nuevas formas de explotación.

\section{REFLEXIONES FINALES}

A lo largo de este artículo hemos realizado un recorrido por las tendencias hegemónicas en materia de políticas habitacionales dentro del territorio de la Ciudad de Buenos Aires, señalando sus limitaciones en cuanto a la satisfacción de las necesidades de las mujeres de sectores populares. En este sentido, tanto por sus características arquitectónicas como por el predominio de las localizaciones en áreas periféricas de la Ciudad (con insuficiencia de bienes y servicios), las políticas que convierten a las mujeres de bajos ingresos en sus destinatarias dejan sin resolver aspectos clave de sus derechos a la vivienda y la ciudad. 
Asimismo, enfatizamos en el carácter desarticulado de estas políticas sin que aborden el problema de la pobreza en forma integral y con un enfoque que trascienda las miradas meramente asistenciales, conteniendo la heterogeneidad de situaciones que se presentan en la realidad social. Junto con un aumento del déficit habitacional, la falta de articulación entre las políticas de vivienda, de acceso al suelo urbano y de provisión de servicios e infraestructura abonan la consolidación de procesos de segregación socioespacial en el ámbito porteño que, a su vez, atentan contra la posibilidad de avanzar hacia una ciudad democrática.

Frente a estas tendencias hegemónicas, focalizamos en las características del Programa de Autogestión para la Vivienda como alternativa que promueve procesos organizados de producción social del hábitat, donde la autogestión de recursos económicos y técnicos generan impactos materiales y simbólicos en la vida de las mujeres y su relación con el espacio urbano. Por otro lado, el PAV reveló ser un antecedente potente para pensar en el diseño e implementación de nuevas políticas habitacionales que incorporen un enfoque de género capaz de contener las particularidades, prioridades y requerimientos de las mujeres y varones con relación al espacio urbano, por medio del compromiso de los propios usuarios y usuarias con la gestión de su hábitat.

Para concluir, podemos sostener que el tipo de miradas conceptuales y empíricas que abordan el cruce entre mujeres, hábitat y políticas públicas aportan datos significativos para pensar en nuevos instrumentos de acceso a la vivienda adecuada por parte de las mujeres, que permitan dar pasos hacia la construcción de ciudades donde no predomine la lógica de la ganancia, sino la de las necesidades sociales y de género.

\section{BIBLIOGRAFÍA}

CELS (2009): Infantilización del déficit habitacional en la Ciudad de Buenos Aires [on line]. Disponible en: http://www.cels.org.ar/common/documentos/infantilizacion_del_ deficit.pdf [Recuperado el 9 de octubre de 2011].

Coraggio, José Luis (1998): Economía popular urbana: una nueva perspectiva para el desarrollo local. Programa de Desarrollo Local, Instituto del Conurbano. Buenos Aires: UNGS.

Cravino, María Cristina (2008): Vivir en la villa. Relatos, trayectorias y estrategias habitacionales. Los Polvorines: ICO / UNGS.

Ducci, María Elena (1994): "Políticas de vivienda y mujer”, en Eure, Vol. 20, No 59, pp. 73-91. Santiago de Chile.

Falú, Ana (2003): "La ciudad y las mujeres: hábitat y género", en Educación para la inclusión a lo largo de la vida [on line]. Seminario virtual, Proceso preparatorio para la CONFITEA V + 6, GEO - ICAE. Disponible en: http://www.icae.org.uy/spa/ sgeoseminario4.html\#ciumuj [Recuperado el 9 de octubre de 2011]. 
Foro Mundial de las Mujeres (2004): Carta por el Derecho de las Mujeres a la Ciudad [on line]. Disponible en: http://www.hic-al.org/documento.cfm?id_documento=1089 [Recuperado el 10 de octubre de 2011].

Gil y de Anso, María Laura y Ramos, Julia (2010a): "De rupturas y continuidades", en Revista Ciudades, No 88, octubre-diciembre, pp. 17-23. Red Nacional de Investigación Urbana, Puebla, México.

- (2010b): "Derecho de las mujeres a la vivienda: tendencias y desafíos en América Latina", en Boletín Derecho a la vivienda y a la ciudad en América Latina, No 10, diciembre, pp. 12-15.

(2011): "La casa, el barrio y la ciudad: algunas consideraciones de género a partir de la experiencia del Movimiento de Ocupantes e Inquilinos", en Di Virgilio et al. (comps.): La cuestión urbana interrogada. Transformaciones urbanas, ambientales y políticas públicas en Argentina, pp. 385-419. Buenos Aires: Café de las Ciudades.

Gobierno de la Ciudad Autónoma de Buenos Aires (2008): Diagnóstico de la emergencia habitacional en la Ciudad Autónoma de Buenos Aires, Informe Final. Buenos Aires: Convenio FADU-UBA / Ministerio de Derechos Humanos y Sociales.

(2011): Vivienda transitoria [on line]. Disponible en: http://www.buenosaires. gov.ar/areas/des_social/atencion_inmediata/viv_transitoria.php?menu_id=31129 [Recuperado el 10 de octubre de 2011].

Gomà, Ricard y Subirats, Joan (1999): Políticas públicas en España. Barcelona: Editorial Ariel.

Herzer, Hilda (2008): Con el corazón mirando al sur: transformaciones en el sur de la ciudad de Buenos Aires. Buenos Aires: Espacio Editorial.

Herzer, Hilda; Di Virgilio, Mercedes y Rodríguez, María Carla (2006): Género y urbanización. Buenos Aires: Mimeo.

Jelin, Elizabeth (1993): ¿Ante, de, en, y? Mujeres y derechos humanos. Lima: Red Entre Mujeres.

Massolo, Alejandra (1999): "Las mujeres y el hábitat popular: ¿cooperación para la sobrevivencia o para el desarrollo?", en Boletín CF+S, N 19 [on line]. Disponible en: http://habitat.aq.upm.es/boletin/n19/aamas.htm/ [Recuperado el 10 de octubre de 2011].

Michaud, Anne (2007): "Compartir nuestros conocimientos para actuar mejor: un foro de intercambios en línea sobre los desafíos de la igualdad de género en las ciudades", en Mujeres y Ciudades International [on line]. Disponible en: http://WWW. mujeresyciudades.org [Recuperado el 10 de octubre de 2011]. 
Naciones Unidas (2010): El progreso de América Latina y el Caribe hacia los Objetivos de Desarrollo del Milenio. Desafíos para lograrlos con igualdad. Santiago de Chile: Naciones Unidas.

Oszlak, Oscar (1991): Merecer la ciudad. Los pobres y el derecho al espacio urbano. Buenos Aires: CEDES-Humanitas.

Rainero, Liliana y Falú, Ana (1995): "Hábitat urbano y políticas públicas. Una perspectiva de género", en Hábitat urbano: una visión de género. Córdoba: CISCSA.

Rodríguez, María Carla (2002): "Producción social del hábitat, cooperativismo autogestionario y derecho a la ciudad", en Mundo Urbano, № 17, [on line]. Buenos Aires, Argentina. Disponible en: http://Www.mundourbano.unq.edu.ar/index.php/ ano-2002/55-numero-17 [Recuperado el 20 de marzo de 2010].

--------- (2009): Autogestión, políticas del hábitat y transformación social. Buenos Aires: Espacio Editorial.

Rodríguez, María Carla et al. (2007): Producción social del hábitat y políticas en el Área Metropolitana de Buenos Aires: historia con desencuentros. Buenos Aires: IIGG / FSOC / UBA.

Saborido, Marisol (1999): Ciudad y relaciones de género. Santiago de Chile: CEPAL, Unidad Mujer y Desarrollo.

Salazar Cruz, Clara Eugenia (1999): Espacio y vida cotidiana en la ciudad de México. Centro de Estudios Demográficos y de Desarrollo Urbano. México: El Colegio de México.

Thomasz, Ana Gretel (2008): "Historia y etnografía de una normativa polémica: la Ley 341 y el Programa de Autogestión para la Vivienda", en Cuadernos de Antropología Social, № 28, pp. 127-149. FFyL / UBA. Disponible en: http://www.scielo.org.ar/pdf/ cas/n28/n28a07.pdf [Recuperado el 9 de octubre de 2011].

Villarreal, Juan (1996): La exclusión social. Buenos Aires: FLACSO / Norma. 